Article

\title{
Green Supply Chain Management and Its Impact on Consumer Purchase Decision as a Marketing Strategy: Applying the Theory of Planned Behavior
}

\author{
Changjoon Lee ${ }^{1} \mathbb{D}$, Soyoun $\operatorname{Lim}^{2, *}$ and Byoungchun $\mathrm{Ha}^{1}$ \\ 1 Department of Logistics, Services, Operations Management, Sogang University, Seoul 04107, Korea; \\ cjlee0825@hanmail.net (C.L.); habc@sogang.ac.kr (B.H.) \\ 2 Department of Global Service Management, Sogang University, Seoul 04107, Korea \\ * Correspondence: limsy@sogang.ac.kr
}

Citation: Lee, C.; Lim, S.; Ha, B. Green Supply Chain Management and Its Impact on Consumer

Purchase Decision as a Marketing Strategy: Applying the Theory of Planned Behavior. Sustainability 2021, 13, 10971. https://doi.org/10.3390/ su131910971

Academic Editor: Riccardo Testa

Received: 6 August 2021

Accepted: 29 September 2021

Published: 2 October 2021

Publisher's Note: MDPI stays neutral with regard to jurisdictional claims in published maps and institutional affiliations.

Copyright: (c) 2021 by the authors. Licensee MDPI, Basel, Switzerland. This article is an open access article distributed under the terms and conditions of the Creative Commons Attribution (CC BY) license (https:// creativecommons.org/licenses/by/ $4.0 /)$.

\begin{abstract}
This study examines the impact of green supply chain management (GSCM) on consumers environmentally friendly purchase behavior. We surveyed 283 consumers and analyzed the data using SPSS 18.0, AMOS 18.0, and verified them with structural equation modeling. To support the primary data analysis results, we conducted focus group interviews (FGIs) of 16 consumers. According to the primary data analysis, consumers' subjective norms and perceived behavioral control positively influence GSCM. However, attitude did not have a significant influence. In the FGI, consumers show a highly positive attitude and purchase intention toward the GSCM of companies. However, they exhibit mistrust and lower purchase intentions toward advertising or marketing campaigns promoting GSCM to consumers. In contrast, the influence of subjective norms was found to be different for different products. In addition, a high price-regarded as the biggest barrier among perceived control factors-raises purchase intentions if consumers are provided with good and transparent information about green products. Thus, this study buttresses the fact that if a company uses GSCM practices as an eco-friendly marketing strategy that reduces consumer distrust and considers product characteristics, it can have a positive effect on consumers' decision to purchase eco-friendly products.
\end{abstract}

Keywords: theory of planned behavior; internal GSCM; external GSCM; consumer eco-friendly purchasing behavior

\section{Introduction}

There is a growing body of research that focuses on the exploration of environmental issues. Environmental problems are receiving increased attention, especially among businesses and consumers. Consistent interests and concerns about the environment are making a difference in government regulations, corporate activities, and consumer behavior. The Ministry of Environment (MOE) of South Korea has recently reported that the proportion of packaging waste to all household waste has exceeded 30\%. The MOE has announced the implementation of aggressive environmentally friendly policies, including the publication of packaging guidelines and monitoring, in agreement with distribution and logistics companies [1]. In addition, the Korea Integrated Logistics Association has declared that the industry will actively seek to build an environmentally friendly logistics system. As the government has increasingly tightened environmental regulations to fight persistent pollution and climate change, corporations are responding by adopting different environmental management strategies. Against this backdrop, green supply chain management (GSCM) has emerged as an effective strategy. It enables corporations to mitigate environmental risks and legal responsibilities while building a positive corporate image [2]. Furthermore, GSCM is the main driver of sustainable management and competitive advantage in today's business landscape. 
The influence of corporations going "green" has started to reach general consumers beyond the business world. Consumer perceptions about green products have changed, which has led to changes in purchase behavior, characterized by ethical, green, or sustainable consumption [2]. Embracing these behavioral changes in consumption patterns and understanding and analyzing consumer motivation and behavior have become important strategies for business managers [3]. However, many studies point out that environmentally friendly marketing strategies can increase consumers' mistrust without a positive effect on their purchase of green products [4-6]. Within this context, we examine GSCM-based marketing strategies to encourage consumers to buy green products.

First, we apply the theory of planned behavior (TPB), while explaining the variables predicting consumer behavior. The TPB, which sets attitude, subjective norms, and perceived behavioral control as antecedents, intention as a mediating variable, and behavior as a dependent variable, is an extended model of the theory of reasoned action (TRA). TPB is an optimized model for measuring the factors influencing consumer intentions and behavior. It is widely used as a framework for research on environmentally friendly behaviors [7]. It is also the most useful and commonly used theory in the psychological field to explain human behavior, including the prediction of consumer purchase behavior [8].

As for the framework for environmental activities in corporations, we examine GSCM. A GSCM strategy is expected to enable corporations to make an authentic voice for environmental protection. D'Souza and Taghian [9] argue that as consumers interested in buying green products turn their attention from external to internal activities of a corporation, businesses need to focus on environmentally friendly manufacturing processes or decision-making. In addition, Ta et al. [10] state that consumers can be instrumental in driving value creation upstream as a partner for the success of corporations. Evidence suggests that with growing consumer interest in internal corporate activities, it is possible to engage consumers in the framework that used to be measured as a corporation's internal practices to create new values [11].

Environmental issues are expected to accelerate the government's implementation of environmental policies and the adoption of green management strategies by corporations. Thus, it is important to examine the relationship between GSCM and consumers as a strategy to become an environmentally friendly company preferred by consumers. However, previous research on GSCM has only measured organizational performance among employees and manufacturers [12-14]. Consumers' green purchase behavior is examined mostly from the perspective of marketing management [15], with measurements focused only on the organic food category $[3,16]$. To overcome these limitations, this study examines the influence of GSCM on consumers' purchase decisions. We divided GSCM into internal/external activities based on the framework suggested by Zhu and Sarkis [17] to verify their influence [14]. Furthermore, we considered corporate environment activities in light of internal activities and expand the object of measurement to general environmentally friendly consumer goods. Next, we conducted focus group interviews (FGIs) for an in-depth analysis of the primary verification results. This step aims to supplement the main research methodology of this study through quantitative research.

In this study, we attempt to verify the positive influence of GSCM on consumers' purchasing behavior for green products.

\section{Theoretical Background}

Through a theoretical examination, this study set attitude, subjective norms, perceived behavioral control, and purchase behavior as the variables of TPB, and divided GSCM into internal and external activities. Based on this approach, we explain the concepts involved and suggest a research model for their interaction.

\subsection{Theory of Planned Behavior (TPB)}

The theory of planned behavior (TPB) explains the mechanism by which attitude, subjective norms, and perceived behavioral control, based on beliefs, leads to intentions 
and behaviors [18]. TPB has been found to be a viable social-cognitive model that predicts human behaviors and appropriately explains behavior change interventions regarding environmentally friendly behaviors [19]. It is specially optimized for research on green product purchase intentions and behaviors. The TPB has been widely used as a framework for related studies [7]. Ajzen [18] explained that TPB is open for revision by adding new variables to its components.

\subsubsection{Attitude}

Attitude, a component of TPB, is measured as the degree to which a person has a positive or negative evaluation of behavior. Attitude entails the consideration of the antecedents of human behavior [18]. Paul et al. [7] also showed that attitude is the most influential TPB factor. The higher an individual's interest in the environment, the greater is the influence of attitude. De Leeuw et al. [19] explained attitude as a predictor of behavior based on psychology. A positive attitude is the main factor that leads to positive behavior. Yadav and Pathak [3] also argue that attitude is the key factor influencing purchase intentions, as buying green products creates a positive social image.

On the contrary, Moser [5] finds that attitude is least associated with environmentally friendly purchase behavior. Olson [6] focused on the purchase of environmentally friendly cars. Both studies find that attitude is not related to consumer behavior. These inconsistent findings indicate that the relationship between attitude and behavior may differ depending on the antecedents and objects to be measured.

\subsubsection{Subjective Norms}

Subjective norms, another factor under TPB, determine whether to do something based on social pressure. Normative beliefs and motivations lead to behavior [18]. This is perceived as the social pressure to engage or disengage in a specific behavior. Positive subjective norms are associated with positive behavior [20]. Subjective norms are also explained as an influence, and the normative expectations of the important others we care about, including family, friends, or business partners [7,15]. Yadav and Pathak [3] indicated that subjective norms have a significant impact on green purchase intentions and behaviors. Han and Kim [15] showed that subjective norms positively influence revisit intentions regarding environmentally friendly hotels. Hsu et al. [21] suggested that subjective norms have a positive correlation with the purchase intentions of environmentally friendly personal care products. Liobikienè et al. [8] also insisted that subjective norms influence green purchase behavior directly and most significantly.

However, Paul et al. [7] found that there is no or little, if any, relation between subjective norms and green purchase behavioral intentions. However, a review of more studies on subjective norms for social groups reveals that there are far more positive correlation results, and it is safe to establish a positive correlation between subjective norms and green purchase behavior [22].

\subsubsection{Perceived Behavioral Control}

Perceived behavioral control is a person's perception of the ease or difficulty of performing the behavior of interest and controlling beliefs. Perceived power contributes to a person's perceived behavioral control. It is based on beliefs concerning access to the necessary resources to promote or inhibit behavior, including time, money, and opportunities [18]. Ajzen [18] adds "perceived behavioral control" to TRA to overcome the limitation of "incomplete volitional control," and develops TPB.

By introducing the construct, "perceived behavioral control," TPB can reflect the expected obstacles and past experiences to predict a person's behavior more specifically [20]. Perceived behavioral control has been found to be a positive factor that influences green purchasing behavior [3,7].

On the contrary, Arvola et al.'s [23] study on organic food purchase intentions shows that perceived behavioral control has no influence on behavior. Moser [5] argues that 
perceived behavioral control cannot generally be applied to green purchase behavior. However, it is the only factor that directly influences the behavior in the TPB model suggested by Ajzen [18]. In addition, it can be used as an important potential variable in research on the relationship between the environment and consumer behavior [19].

\subsubsection{Behavior}

Behavior reflects the general disposition of an individual, the specific event, and the situation [18]. It can be triggered by enhancing consumers' positive behavioral beliefs, raising awareness of important others, and forming control beliefs that lower barriers and lead to behavior [19]. The pro-environmental behavior of consumers refers to behavior that has the lowest harmful impact, or even benefits the environment [24]. This aspect includes behavior toward activities involving the use of environmentally related goods and services, or recycling products to decrease waste [3]. Consumers' environmentally friendly attitude, in addition to subjective norms and perceived behavioral control, is a positive factor influencing green purchase behavior [3,19]. Recently, increasing environmental awareness has further encouraged environmentally friendly purchase behaviors, including green consumption and ethical consumption [3].

In short, the TPB components constitute a mechanism that best predicts and explains social behaviors [20] and are quoted most frequently in research on environmentally friendly behavior $[7,16]$. However, studies related to TPB and environmentally friendly behaviors have mostly focused on corporate marketing practices. The results vary depending on the objects measured and the variables considered. With consumers' attention concentrated on the manufacturing process of green products [9], this study aims to identify the influence of GSCM on consumer behavior by allowing consumers to access information about the internal environmental activities of corporations. In addition, we conduct an in-depth examination of consumer purchase behavior outcomes using the TPB variables.

\subsection{Green Supply Chain Management (GSCM)}

GSCM integrates environmental thinking into the existing SCM [14]. Sarkis et al. [13] defined GSCM as a conceptual and systematic integration of reverse logistics, marketing, operation, and purchasing activities with a focus on the environment. GSCM is designed from the perspective of employees to promote environmental practices in and between organizations in the logistics industry [14,25]. Having been measured only from the perspective of employees, GSCM is now emerging as a practice, used externally to increase market share with a positive image and internally, to reduce material costs and increase profits. This shift is because consumers' demand for sustainable products and services is rising, and government regulations are tightening $[13,26]$. Thus, it seems necessary to include consumer evaluations and perspectives in GSCM.

Zhu et al. [14] divided GSCM, which used to be defined as an integrated concept for successful organizational performance, into internal and external GSCM based on the organizational boundary of the manufacturers. In this study, we use this bifurcated GSCM framework to help consumers better understand the concept and roles of GSCM.

\subsubsection{Internal GSCM}

Internal GSCM practices are the environmental management activities of organizations to manufacture green products [27]. The introduction and implementation of internal GSCM practices will promote the expansion of external GSCM practices, leading to the success of the GSCM system [25]. Zhu et al. [27] insisted that a corporation cannot successfully establish a GSCM system without first implementing internal GSCM practices. Zhu et al. [14] also found that internal GSCM practices have a positive (+) impact on external GSCM practices as antecedents. Internal GSCM practices comprise internal environmental management (IEM) and eco-design (ECO). ECO is measured in the domain of both internal and external practices or is explained as an independent factor $[14,25]$. Therefore, it was excluded from this study because it was considered insufficient to explain 
internal GSCM. Zhu and Sarkis [17] explained that IEM is the most important practice for determining the success of a GSCM system. They divided the IEM into four factors:

- Total quality environmental management: contribution of the organization in improving environmental performance in the process of pursuing quality improvement and environmental performance by adopting and developing innovative technologies in cooperation with suppliers [17].

- Environmental compliance and auditing program: monitoring compliance with domestic and international environmental regulations and excessive energy consumption of suppliers [14].

- ISO 14000 certification: preference over the certified suppliers certified environment [25].

- Commitment and support from managers and employees: environmental support and commitment from top management, and middle and high-level managers [14].

Dou et al. [28] demonstrated that support from managers is a key factor in the successful introduction and implementation of the GSCM system. However, it is not consistently used to measure IEM [14,27] or as an independent factor [25]. Therefore, support from managers is excluded from this study as a representative factor to explain IEM.

\subsubsection{External GSCM}

External GSCM practices cannot be executed without the cooperation and support of other external parties such as suppliers, customers, and stakeholders [25]. External GSCM practices comprise the following factors:

- Green purchasing (GP) is an activity that integrates supplier management and material selection from an environmental viewpoint [27].

- Customer cooperation with environmental concerns (CC): cooperation with customers who require a cleaner production process, and the process of producing environmentally sustainable products, including environmentally friendly packaging [12].

CC is cooperation with other external parties, such as suppliers, customers, and stakeholders, and is also included in CC [14]. Therefore, CC enables companies to cooperate with consumers through environmentally friendly marketing, inform consumers about the companies' efforts to improve the environment, and the differences in the companies' products from general products [29]. Investment recovery (IR) is also described as a component of external GSCM practices. However, it is not a core factor and has not been implemented in developing nations because of the lack of recycling facilities and technologies [17,27]. Hence, it was excluded from this study.

Through this literature review, internal GSCM practices were found to be controllable in corporations. However, external GSCM practices, including external cooperation with the government, social groups, consumers, and other stakeholders [25], require differentiated operational strategies. This situation raises the need to measure the GSCM framework from the stakeholders' viewpoint, in addition to that of the employees, such as the environmental, management, and economic performance of organizations. Furthermore, the latest studies on SCM argue that corporations can create new value and gain a competitive advantage by incorporating customer opinions and cooperation in the SCM process, which is a typical B2B domain $[10,11]$. The role of downstream changes includes the viewpoint of consumers, the end point of SCM, and the correlation between consumers. However, the supply chain process has rarely been investigated [10]. This study incorporates end consumers in the GSCM measurement, in addition to the employees of the organization, to fill this gap. Based on this approach, we identify whether GSCM, as an internal environmental practice of corporations, influences customer behavior.

\section{Developing Hypotheses and Research Model}

Based on the preceding research, we suggest the TPB components as antecedents that can influence GSCM practices and verify how they influence consumers' green purchase behavior. 


\subsection{Attitude, Subjective Norms, Perceived Behavioral Control, and Internal GSCM Practices}

Corporations try differentiated strategies as they incorporate customer opinions in the SCM process, which used to be run from the B2B perspective [30]. Zhu et al. [27] insist that the responsibility of manufacturing and production should be extended to end consumers. By incorporating the viewpoint of end consumers in selecting environmentally friendly suppliers, consumers' opinions can be reflected in the internal decision-making process [11]. This process implies that SCM is not just an internal corporate practice. Rather, it emerges as a competitive strategy through collaboration with consumers. GSCM is an SCM activity that integrates environmental aspects [14]. Considering these changes in SCM, new values should be created, and new strategies should be formulated by incorporating consumer viewpoints and opinions into the GSCM process.

In contrast, the correlation between internal GSCM practices and consumers in the existing literature is summarized as follows: Wu and Jang [31] found that ISO certification creates a positive consumer attitude by raising trust in product quality and increasing purchase intention. Rahbar and Abdul Wahid [32] stated that labeling that describes the manufacturing process of green products enhances the positive attitude of consumers and encourages purchase behavior. Since the manufacturing process of green products and ISO 14000 certification are all components of internal GSCM practices [17], it may be appropriate to say that internal GSCM practices and consumer attitudes have a positive correlation. In addition, consumers buying green products can create positive images as well as a sense of responsibility [29]. Positive past experiences [16] have a positive (+) influence on subjective norms and perceived behavioral control. Therefore, internal GSCM practices, which are typical internal practices of corporations, can be influenced by end consumers. In summary, it is conceived that consumer attitude, subjective norms, and perceived behavioral control influence internal GSCM practices. In this context, we set the following hypotheses:

Hypothesis 1 (H1). Attitude has a positive (+) effect on internal GSCM practices.

Hypothesis 2 (H2). Subjective norms have a positive (+) effect on internal GSCM practices.

Hypothesis 3 (H3). Perceived behavioral control has a positive (+) effect on internal GSCM practices.

\subsection{Attitude, Subjective Norms, Perceived Behavioral Control, and External GSCM Practices}

The more environmental concerns consumers have, the higher the environmental responsibility that upstream players in SCM take [28]. With growing interest in environmental issues, consumers have turned their attention to the internal environmental activities of corporations [9], thus increasing the need for environmental strategies through collaboration between internal environmental activities and consumers. SCM strategies and process changes can create new opportunities [10] and provide a breakthrough to internal innovation and a solution to persistent problems by building a positive image of SCM among consumers [11]. These findings indicate a positive relationship between SCM and consumer collaboration. GSCM has also been introduced to respond to consumer demands and pressure on the social responsibility of corporations [14]. The trend of operational changes in SCM is a sign that consumers will play a bigger role in external GSCM practices, where customer collaboration is crucial from an environmental perspective.

Meanwhile, attitude, subjective norms, and perceived behavioral control—influencing consumer behavior-improve through information about employees' environmental activities and the processes within the organization [15]. Yadav and Pathak [3] explained that customer collaboration could raise environmentally friendly value and trust in corporations, leading to a more positive attitude, subjective norms, and perceived behavioral control. This statement means that corporations can attract positive attitudes, subjective norms, and perceived behavioral control by communicating green product information with consumers through external GSCM practices. It can also alleviate the burden on corporations 
imposed by consumers' expectations of corporate social responsibility (CSR) regarding the environment [27]. Thus, it is expected that external GSCM practices are positively influenced by consumers' attitudes, subjective norms, and perceived behavioral control.

Hypothesis 4 (H4). Attitude has a positive (+) effect on external GSCM practices.

Hypothesis 5 (H5). Subjective norms have a positive (+) effect on external GSCM practices.

Hypothesis 6 (H6). Perceived behavioral control has a positive (+) effect on external GSCM practices.

\subsection{Internal GSCM and Green Purchase Behavior}

Customers' green purchase behavior is no longer positively influenced by the commercial advertising campaigns of corporations or the media [4]. Instead, internal practices such as environmentally friendly purchase of raw materials, manufacturing processes, and recycling influence consumers' final decision-making [9]. As Boyce and Mano [11] point out, consumers are decision-makers who lead new SCM strategies. Consumer views and collaboration need to be incorporated into the SCM process, which was previously run from a B2B perspective. Against this backdrop, corporations need to change their internal environmental management strategies to incorporate consumer purchase behavior and perspectives.

GSCM is an important corporate environmental strategy that should be introduced first to improve corporate image and environmental performance. The successful introduction of internal GSCM practices is key to the success of GSCM [14]. Internal GSCM practices, which are comprehensive and extensive, require a large number of resources and investments [25]. However, the effect of the internal environmental effort on consumer behavior, including ISO certification, has not been fully established [31]. GSCM has been adopted by many corporations to comply with government regulations and meet consumer demands [27], with growing environmental awareness among consumers. This move indicates that internal GSCM practices are influenced by consumers as well. Consumers are increasingly demanding more internal environmental practices from corporations, but the integration of B2B and B2C sector operations is still lacking [33]. As the first step in connecting corporate environmental activities with consumers, it is necessary to incorporate consumer perspectives into the internal GSCM framework. Based on these findings, we propose the following hypothesis:

Hypothesis 7 (H7). Internal GSCM practices have a positive (+) effect on consumers' green purchasing behavior.

\subsection{External GSCM and Green Purchase Behavior}

Han and Kim [15] argued that corporations need to link environmentally friendly marketing with internal environment programs to attract consumers' positive attitudes. Olson [6] insisted that marketing strategies emphasizing the environmental design of a product can alleviate consumer mistrust and narrow the gap between the perceived value of green products and purchase behavior. Zhu et al. [27] suggested that a combination of external GSCM practices and marketing activities reduces the environmental burden of corporations' SCM. These findings indicate that corporations need to adopt an integrated approach to corporate marketing and internal environmental practices to promote consumers' green purchase behavior.

External GSCM can be used to promote suppliers' green purchasing by using environmentally friendly suppliers in transactions. However, in general, consumers do not have access to information about manufacturers or suppliers' internal environmental activities, except for vendors. External GSCM can provide an opportunity to communicate with consumers about corporate internal environmental efforts and enhance a positive corporate image, leading to consumer purchase behavior. Moreover, according to Ta et al. [10], it is possible to create new values in SCM through consumer monitoring of suppliers and 
return management collaboration. External GSCM practices also enable consumers to check internal environment activities and contribute opinions to the process. Thøgersen et al. [34] explained that consumers tend to be more highly involved in green products than general products, which more frequently leads to purchase behavior. This perspective will promote consumer involvement in external GSCM practices even more, with a positive $(+)$ effect on purchase behavior.

In summary, the literature review suggests that corporate external GSCM practices positively influence consumer behavior. Since external GSCM practices include both downstream and upstream elements [25], they are expected to have a positive influence on consumer purchase behavior through the collaboration of consumers in internal environmental activities. Accordingly, our last hypothesis is as follows.

Hypothesis $\mathbf{8}$ (H8). External GSCM practices have a positive (+) effect on consumers' green purchasing behavior.

We establish a research model to explain the causal relationships among TPB, GSCM, and purchase behavior in the relationship between corporations and consumers, as shown in Figure 1.

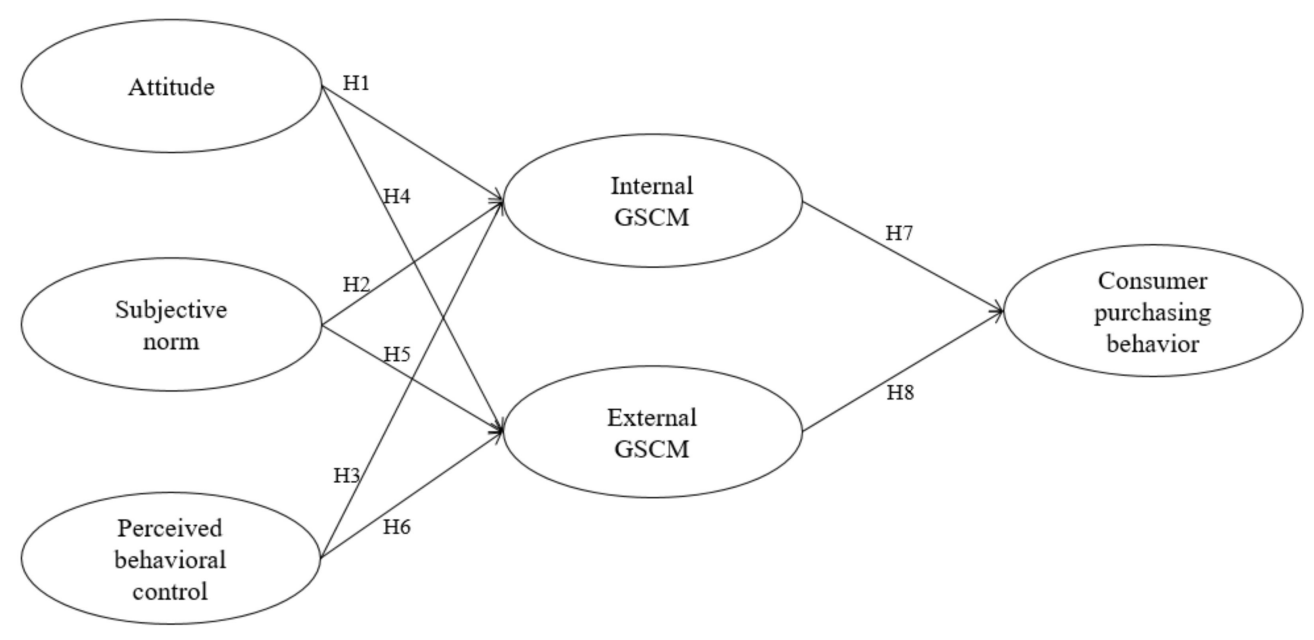

Figure 1. Research model.

\section{Research Methodology}

\subsection{Data Collection}

We set the variables based on a literature review. To collect data for empirical verification, we surveyed consumers. First, we conducted a pretest for 10 surveyors and a survey assistant to verify the survey content and correct any errors. We then conducted an online survey between October and November 2019, commissioned to "ENTRUST," a Korean professional sampling company. A total of 575 copies were distributed, and 283 valid responses were returned, excluding incomplete or insincere responses (valid return rate $=49.39 \%$ ). The survey questions consisted of demographic factors, based on existing studies. Of the respondents, $49.8 \%$ were male and $50.2 \%$, female; $63.3 \%$ were single; $29.7 \%$ were in their $20 \mathrm{~s}$, and $31.1 \%$ were in their $30 \mathrm{~s}$. In terms of education, more than half of them graduated from university (54.4\%); office workers were $36.7 \%$ and students comprised $27.2 \%$, which was the highest. To collect secondary data, FGIs were conducted on 16 adults who purchased green products.

\subsubsection{Measurement of Variables}

Based on previous studies, we considered six potential factors and 18 measurement variables to ensure the content validity of the potential variables. The details of the 
measurement variables are presented in Table 1. All questionnaire items were measured using a 7-point Likert scale, indicating 1-strongly disagree, 4-neither agree nor disagree, and 7-strongly disagree.

Table 1. Operational definition of the variables.

\begin{tabular}{|c|c|c|}
\hline Variable & Measurement Item & References \\
\hline Attitude & $\begin{array}{c}\text { Willingness to engage in environmental protection by } \\
\text { purchasing green products } \\
\text { Degree of purchase motivation according to environmental concerns } \\
\text { Degree of purchase value of green products }\end{array}$ & \multirow{4}{*}{$\begin{array}{l}\text { Ajzen [20]; } \\
\text { De Leeuw et al. [19]; } \\
\text { Han and Kim [15]; } \\
\text { Liobikienè et al. [8] }\end{array}$} \\
\hline $\begin{array}{l}\text { Subjective } \\
\text { Norm }\end{array}$ & $\begin{array}{l}\text { Intention to buy products recommended by friends } \\
\text { Intention to buy products influenced by news and articles } \\
\text { on the environment } \\
\text { Intention to buy products influenced by } \\
\text { environmentally friendly companies }\end{array}$ & \\
\hline $\begin{array}{l}\text { Perceived } \\
\text { Behavioral } \\
\text { Control }\end{array}$ & $\begin{array}{l}\text { Time required to buy green products } \\
\text { Ease of buying green products } \\
\text { Willingness to buy green products }\end{array}$ & \\
\hline $\begin{array}{l}\text { Consumer purchasing } \\
\text { (eco-friendly product) } \\
\text { behavior }\end{array}$ & $\begin{array}{l}\text { Whether having good experience about green products } \\
\text { Choice between green products and general products } \\
\text { Whether to choose environment-friendliness certified products }\end{array}$ & \\
\hline Internal GSCM & $\begin{array}{l}\text { Quality management of the internal facilities of the organization } \\
\text { Compliance with environment protection regulations, management, } \\
\text { and audit program } \\
\text { Obtaining environmentally friendly certification }\end{array}$ & \multirow{2}{*}{$\begin{array}{l}\text { Zhu and Sarkis [17]; } \\
\text { Zhu et al. [25]; } \\
\text { Zhu et al. [14] }\end{array}$} \\
\hline External GSCM & $\begin{array}{l}\text { Whether to transact with environmentally friendly suppliers } \\
\text { GSCM activities and communication with suppliers } \\
\text { GSCM activities and communication with consumers }\end{array}$ & \\
\hline
\end{tabular}

\subsubsection{Reliability and Validity Tests}

This study conducted a path analysis using potential variables, utilizing AMOS 18.0, to test the hypotheses to investigate the relationship between TPB theory, GSCM, and purchase behavior. A reliability test was performed for each factor prior to the path analysis. Cronbach's alpha was measured using the SPSS 18.0. From the reliability tests, the range of Cronbach's alpha values of all potential variables ranged from 0.755 to 0.846 . Since the standardized Cronbach's alpha is higher than 0.7 , it can be said that the reliability of the study was secured [35].

Next, a confirmatory factor analysis of the measurement model was conducted using AMOS 18.0. The fitness of the measurement model was CMIN/DF $=1.882, \mathrm{GFI}=0.921$, $\mathrm{TLI}=0.943, \mathrm{CFI}=0.956, \mathrm{NFI}=0.912$, and RMSEA $=0.056$. These values were considered to be acceptable. In the exploratory factor analysis, Bartlett's sphericity test (2444.116, significance $=153, \mathrm{df}=0.000)$ and Kaiser-Meyer-Olkin tests (0.893) proved that the correlation between variables was significant [36].

The convergent validity of the factors used in this study was investigated through construct reliability (CR) and average variance extracted (AVE). As the construct reliability of each factor is 0.7 , and the average variance extraction value is higher than 0.5 , it can be said that the convergent validity of the factors is secured [36]. The results of the confirmatory factor analysis and convergent validity test for each factor are shown in Table 2. 
Table 2. Results of reliability and convergent validity analysis.

\begin{tabular}{|c|c|c|c|c|c|c|}
\hline Variable & Items & $\begin{array}{c}\text { Cronbach's } \\
\text { Alpha }\end{array}$ & $\begin{array}{c}\text { Corrected } \\
\text { Item-to-Total } \\
\text { Correlation }\end{array}$ & $\begin{array}{l}\text { Cronbach's } \\
\text { Alpha if Item } \\
\text { Deleted }\end{array}$ & CR & AVE \\
\hline \multirow{3}{*}{ Attitude } & ATT1 & \multirow{3}{*}{0.846} & 0.744 & 0.762 & \multirow[t]{3}{*}{0.821} & \multirow[t]{3}{*}{0.607} \\
\hline & ATT2 & & 0.691 & 0.818 & & \\
\hline & ATT3 & & 0.719 & 0.782 & & \\
\hline \multirow{3}{*}{$\begin{array}{l}\text { Subjective } \\
\text { Norm }\end{array}$} & SN1 & \multirow{3}{*}{0.816} & 0.618 & 0.804 & \multirow[t]{3}{*}{0.823} & \multirow[t]{3}{*}{0.609} \\
\hline & SN2 & & 0.690 & 0.731 & & \\
\hline & SN3 & & 0.705 & 0.707 & & \\
\hline Perceived & PBC1 & \multirow{3}{*}{0.768} & 0.533 & 0.761 & \multirow[t]{3}{*}{0.821} & \multirow[t]{3}{*}{0.610} \\
\hline Behavioral & PBC2 & & 0.622 & 0.679 & & \\
\hline Control & PBC3 & & 0.674 & 0.609 & & \\
\hline \multirow{3}{*}{ Internal GSCM } & IEM1 & \multirow{3}{*}{0.784} & 0.605 & 0.726 & \multirow[t]{3}{*}{0.787} & \multirow[t]{3}{*}{0.552} \\
\hline & IEM2 & & 0.676 & 0.649 & & \\
\hline & IEM3 & & 0.589 & 0.743 & & \\
\hline \multirow{3}{*}{ External GSCM } & EEM1 & \multirow{3}{*}{0.755} & 0.481 & 0.779 & \multirow[t]{3}{*}{0.823} & \multirow[t]{3}{*}{0.611} \\
\hline & EEM2 & & 0.673 & 0.562 & & \\
\hline & EEM3 & & 0.610 & 0.641 & & \\
\hline Consumer & CPB1 & \multirow{3}{*}{0.761} & 0.520 & 0.767 & \multirow[t]{3}{*}{0.774} & \multirow[t]{3}{*}{0.537} \\
\hline Purchasing & СРB2 & & 0.617 & 0.660 & & \\
\hline Behavior & СРB3 & & 0.652 & 0.608 & & \\
\hline
\end{tabular}

Items details for each construct: ATT1: We believe that purchasing eco-friendly products is a practice of environmental protection. ATT2: When you hear the news about environmental pollution, you will be motivated to purchase eco-friendly products. ATT3: I think it is worth consuming eco-friendly products. SN1: People around me recommended eco-friendly products, so I have considered purchasing them. SN2: I have considered purchasing eco-friendly products due to the influence of environmental news and articles. SN3: I have considered purchasing eco-friendly products due to the influence of ecofriendly companies. PBC1: It takes a lot of time to search for eco-friendly products. PBC2: I can easily buy eco-friendly products anywhere. PBC3: Purchasing eco-friendly products is entirely up to me. IEM1: I think they are doing quality control of the environmentally friendly internal facilities. IEM2: I think there will be a management and supervision program to comply with environmental protection laws. IEM3: I think it is a company that has acquired an eco-friendly management certificate (ISO 14001). EEM1: I think we will do business with environmentally friendly suppliers. EEM2: I think that the information about eco-friendly logistics process is sufficiently informed to consumers. EEM3: I think that the information about eco-friendly products is being sufficiently informed to consumers. CPB1: I have had good experiences with eco-friendly products in the past. CPB2: If you have to choose between eco-friendly products and general brands, buy eco-friendly products. CPB3: Buy products with an eco-friendly certification mark first.

Finally, the results verify the discriminant validity in Table 3. As the correlation coefficient between potential variables is smaller than the AVE square root value of each variable, the discriminant validity of the variables was secured. 
Table 3. Discriminant validity analysis.

\begin{tabular}{ccccccc}
\hline & ATT & SN & PBC & IEM & EEM & CPB \\
\hline ATT & 0.779 & - & - & - & - & - \\
SN & 0.770 & 0.780 & - & - & - & - \\
PBC & 0.558 & 0.712 & 0.781 & - & - & - \\
IEM & 0.532 & 0.452 & 0.449 & 0.743 & - & - \\
EEM & 0.453 & 0.479 & 0.451 & 0.638 & 0.782 & - \\
CPB & 0.587 & 0.723 & 0.667 & 0.460 & 0.438 & 0.733 \\
\hline
\end{tabular}

\subsubsection{Empirical Analysis}

We conducted an empirical analysis of the effect of the TPB components-attitude, subjective norms, and perceived behavioral control-on consumer purchase behavior through GSCM. The results of the analysis of the structural model using the maximum likelihood method were $\mathrm{CMIN} / \mathrm{DF}=2.020, \mathrm{GFI}=0.916, \mathrm{TLI}=0.934, \mathrm{CFI}=0.949, \mathrm{NFI}=0.905$, and RMSEA $=0.060$. These values suggest that the fitness criteria of Hair et al. [35] are generally met. Next, the hypotheses were tested. The results are reported in Table 4 . Six of the eight hypotheses are supported.

Table 4. Hypothesis verification result.

\begin{tabular}{cccccc}
\hline Hypothesis Testing & Estimate & S.E. & C.R. & $\mathbf{P}$ & Analysis Results \\
\hline Hypothesis 1 & 2.142 & 1.157 & 1.852 & 0.064 & Not supported \\
Hypothesis 2 & -4.377 & 2.104 & -2.08 & 0.037 & Supported \\
Hypothesis 3 & 4.982 & 2.141 & 2.327 & 0.020 & Supported \\
Hypothesis 4 & 1.477 & 0.758 & 1.948 & 0.051 & Not supported \\
Hypothesis 5 & -3.042 & 1.430 & -2.128 & 0.033 & Supported \\
Hypothesis 6 & 3.821 & 1.545 & 2.473 & 0.013 & Supported \\
Hypothesis 7 & -1.658 & 0.549 & -3.021 & 0.003 & Supported \\
Hypothesis 8 & 2.793 & 0.633 & 4.415 & 0.001 & Supported \\
\hline
\end{tabular}

Specifically, as can be seen in Table 4, H1 concerns whether attitude, one of the factors in the TPB components, positively affects internal GSCM practices. H1 was not supported, as the path coefficient obtained was insignificant, with a value of $2.142(p>0.05)$. However, other TPB components, namely subjective norms and perceived behavioral control, were found to positively influence internal GSCM practices. The results indicate that TPB components, except consumer attitude, can be antecedents of internal GSCM practices. In contrast, for $\mathrm{H} 4$ on whether attitude has a positive (+) effect on external GSCM practices, the path coefficient is not significant, with a value of $1.477(p>0.05)$. However, subjective norms and perceived behavioral control have a positive $(+)$ effect on external GSCM practices, similar to the relationship between TPB components and internal GSCM practices. These two results indicate that consumer attitude cannot serve as an antecedent to GSCM. However, subjective norms and perceived behavioral control have a positive effect on GSCM practices, leading to purchase behavior.

\subsubsection{Interview Result}

In this study, we conducted FGIs to obtain the opinions of consumers who had purchased green products to provide further support for the results of the primary data analysis. Nyilasy et al. [36] suggested that the difference in consumer attitudes and behavior comes from differences in information. Information about environmentally friendly corporations can also be explained. However, social outcomes and objective information spread through word-of-mouth. Accordingly, information about GSCM is divided into corporate commercials and word-of-mouth of consumers while interviewing consumers. In this way, we were able to obtain answers to the question of why attitude was not an antecedent in the interview, which was not clear in the statistical results. 
First, we interviewed 16 consumers who had experience buying green products via phone or email. The sample included people aged 20-60, working in various industries, and with a monthly income. The interview results indicate that consumers have a positive attitude toward green products. However, a significant proportion of respondents had a negative attitude toward GSCM. Nine out of sixteen participants favored GSCM activities and showed a positive attitude. However, seven participants answered that they would not believe the information presented in TV commercials and media, thus showing a negative attitude. For these reasons, they mention that "corporate marketing is exaggerated or fake, to create an image of an ethical corporation," and "advertising is not enough to gain information or knowledge and it only mentions part of, or temporary environmental activities."

In contrast, they exhibit a totally different response when they obtain information about corporate GSCM activities from family members, colleagues, and friends. Six respondents showed a highly positive attitude, six respondents had a positive attitude, and four showed a neutral or negative attitude.

\section{Discussions, Implications, Conclusions, and Limitations}

\subsection{Discussions}

We examined the influence of the TPB components and the GSCM framework on consumers' green purchase behavior. TPB has been widely applied in research on consumers' green purchase behavior, as it explains the mechanism by which attitude, subjective norms, and perceived behavioral control lead to intentions and behavior. However, there are limitations to previous studies on green products using the TPB. They have only measured TV commercials, media, brochures, and CSR from a marketing perspective. To address these limitations, we extended the scope of measurement and information to the internal environmental activities of corporations. This showcased environmentally friendly manufacturing processes in which corporations invest substantial investment and effort. Thus, corporations can incorporate consumer views on their internal activities to create new value and gain a competitive advantage.

We examined how GSCM, as a corporate internal environmental activity, influences consumers' attitudes, subjective norms, and perceived behavioral control, and, consequently, the green purchase decision-making process. In addition, consumer FGIs were conducted to determine why some factors were rejected, as they cannot be explained by the statistical results. The results of this study were as follows. First, the correlation of attitude with internal and external GSCM practices was found to be insignificant, as H1 and $\mathrm{H} 4$ were rejected. This result is expected from previous studies, and could be due to the "attitude-behavior gap" due to the mistrust of consumers. Ajzen [20] explains that attitude, in general, leads to behavior, but there can be no correlation in the research related to specific behaviors, which requires preliminary measures. Nyilasy et al. [36] point out that corporations' commercials on their environmental activities and word of mouth are two distinct sources of information. Therefore, to address the rejected variable "attitude," we divide how information on GSCM is delivered through two channels, corporate advertising campaigns and word-of-mouth from friends, and conduct FGIs. According to the interviews with 16 consumers, when they get information about GSCM from the corporation's advertising campaigns, $56.25 \%$ of the respondents showed a positive attitude, while $43.75 \%$ were negative. However, $75.00 \%$ showed a positive attitude, and only $25.00 \%$ were negative when they learned about it from their friends or families. It is noteworthy that six interviewees, out of those with a positive attitude, showed a strongly positive attitude that was not observed in the case of advertising campaigns.

The FGI results suggest that the attitude of customers toward GSCM are more strongly influenced by the recommendations of friends than by the corporate advertising campaign. This tendency implies that it is effective to share information about GSCM to enhance consumers' positive attitudes, but a different marketing approach, through non-commercial channels, should be considered. As consumers today are more influenced by word of 
mouth [15], it seems important to work out new strategies, including word-of-mouth or viral marketing, to raise consumers' decision-making in GSCM practices.

Subjective norms were found to be significantly positively correlated with internal and external GSCM practices, as $\mathrm{H} 2$ and $\mathrm{H} 5$ are supported. Subjective norms refer to the belief that an important person or group of people approves and supports green purchase behavior. It is realized as a motive for creating a positive and ethical social image. Consumer interviews supported the same results. The rate is even higher for respondents living with young or elderly parents. This finding implies that the effect of subjective norms can be improved by considering the demographic characteristics. In addition, the results differed according to the use of the green products. Some respondents indicated that they care more about others' opinions about the products used outside than at home, thereby implying that it would be effective to position green products with different degrees of subjective norms based on the products' characteristics [36].

Perceived behavioral control was also found to have a significant effect on internal and external GSCM practices, as $\mathrm{H} 3$ and $\mathrm{H} 6$ are supported. According to the results, the time to buy green products and access was not selected as an impeding factor. On the contrary, many respondents answered that high prices make them hesitant to buy green products. The result of FGIs supports this finding, as 10 interviewees say that high price is an impeding factor. Three out of the 10 answered that they would buy the product regardless of the price, if they have confidence in the environment-friendliness of the company and the environmental benefits of the product. These findings imply that although price is found to be an impeding factor, if a corporation can provide precise information about its environmental activities through GSCM and gain, it will be able to overcome the control barrier of high prices. This finding is in line with the results of previous studies [5,9]. They show that people are willing to pay a higher price when provided with adequate information about green products.

Finally, H7 and H8, "Internal and external GSCM practices have a positive (+) effect on consumers," are supported. Although attitude has no effect on internal and external GSCM practices, it has a positive effect on purchase behavior. In the FGIs, $50 \%$ of the consumers said they have purchase intention when provided with GSCM information through corporate commercials, while $50 \%$ said they do not. On the contrary, when they gain GSCM information from friends, $68.75 \%$ show purchase intention, while $31.25 \%$ do not. The secondary data provide evidence that a reliable environmentally friendly manufacturing process, including GSCM, can turn negative consumer attitudes into positive attitudes, thereby leading to purchase behavior.

\subsection{Implications}

This study had several implications. First, we tried to combine TPB as a consumer behavior model and the GSCM framework as corporate environmental practices. Furthermore, we provided information about corporate internal environment activities by measuring GSCM from the perspective of consumers. This process implies that corporations can collect consumer opinions, while consumers have more trust in the company's environmental efforts when the GSCM framework is extended from the perspective of consumers. Combining GSCM and TPB theory to measure GSCM practices from an end-user perspective provides new insights for companies. Second, for attitude, which was a factor of rejection in the first survey, we conducted FGIs to distinguish our results from previous research on TPB. The interviews provided evidence that GSCM by itself is not sufficient to make consumer attitudes positive. Informing consumers about GSCM practices through trust-based marketing strategies will have a strong positive effect on consumer attitudes and behaviors. The practical implication of this insight is the need to integrate GSCM and marketing strategies. Third, the results of this study suggest that GSCM practices, which companies spend a lot of effort and money on, can be positively used as an ecofriendly marketing strategy by analyzing the impact on consumers' purchasing behavior. In addition, GSCM can be used to create an environmentally friendly image of the company, 
which is different from past advertising strategies. Change the label or notation that is difficult from a business perspective or that only experts can recognize it. Specifically, companies need to provide easy access to GSCM information and knowledge, and make labels and marks of the manufacturing process clearly readable and understandable. Finally, while previous research using TPB has used a limited research model by only measuring intentions [19], this study has theoretical significance as it also incorporates behavior, the final performance variable of TPB. Most research related to TPB ended with purchase intentions. Since companies are likely to be more interested in consumers' purchasing behavior than purchase intention, we broadened the implications of the study by catching variables even in behavior.

\subsection{Conclusions}

Boyce and Mano [11] point out that SCM has been only measured from the perspective of organizational performance, but more focus should be placed on the "people dimension" to maintain a competitive edge. With growing attention to environmental issues, consumers are increasingly concerned about the environment, leading to a higher intention to buy green products. Despite these growing interests, corporations do not overcome the limitations of the green product market, mainly because of an internal employee-centered framework and unreliable marketing. The results of this study confirmed that consumers' attitudes did not affect internal GSCM and external GSCM, and aligned to the "attitudebehavior gap" theory asserted by previous studies. However, additional explanations or studies on these reasons are insufficient. We conducted in-depth consumer interviews to determine the cause and confirmed that the positive effect of information delivery between consumers and consumers is higher than that of companies notifying consumers of GSCM information. Therefore, GSCM is not only measured, developed, and evaluated internally, but if it is used as an eco-friendly marketing element that can spread word of mouth among consumers, it will eventually create a positive attitude and have a positive effect on purchasing behavior. This process will be able to overcome the limitations of the attitude-behavior gap phenomenon. In this context, this study provides evidence that corporations can affect consumers' decision-making by informing consumers about green products and manufacturing processes through GSCM as a new environmentally friendly marketing strategy. In addition, it will make GSCM voluntary and with consumer-oriented environmental practices, instead of being pressured upon by government regulations. We also suggest the possibility of using various environmentally friendly internal frameworks, including but not limited to GSCM as a new marketing strategy. Future research can focus more on the areas of impeding factors to buy green products, including mistrust in green products, conflicts between price and quality, and high-functionality (efficient) green products. Simultaneously, continuous research into instructions that are easy for consumers to understand, and standardized labeling and certification marks will make a greater contribution to the development of research on consumers' green purchase behavior. Finally, the GSCM, in reflecting the consumer's point of view, suggests that companies can gain a competitive advantage in the face of environmental pollution and climate change.

\subsection{Limitations and Suggestions}

Despite these significant implications, the following limitations must be addressed: The first is that GSCM activities designed for internal employees cannot be fully converted to definitions that consumers can understand. Graphs and definitions were provided in a separate section in the questionnaire to explain technical terms, including ISO 14001 certification, quality, and audit. Future researchers may benefit from making the questionnaire easier for the respondents to understand by selecting plain words and easier definitions of GSCM activities.

Furthermore, the relationship between GSCM and consumers has only been discussed sporadically. Although we based our study on the theory of the relationship between SCM and consumers in the existing literature, future studies should pay greater attention to 
the correlation between downstream and internal environment activities, such as GSCM, which, until recently, used to be measured from the B2B perspective.

Finally, green products should be divided according to their characteristics. The categorization and analysis based on the product characteristics will make future research even more significant, as consumers' decision-making processes may differ accordingly.

Author Contributions: All authors contributed to the conception and design of the study. Material preparation, data collection, and analysis were performed by C.L., S.L. and B.H. The first draft of the manuscript was written by C.L., and all authors commented on the previous versions of the manuscript. All authors have read and agreed to the published version of the manuscript.

Funding: This research received no external funding.

Institutional Review Board Statement: There is no aspect of ethical consideration.

Informed Consent Statement: Not applicable.

Data Availability Statement: Not applicable.

Conflicts of Interest: The authors declare no conflict of interest.

\section{References}

1. The Ministry of the Environment. Distribution and Logistics Industry Actively Promotes Eco-Friendly Packaging. 2019. Available online: http:/ / www.me.go.kr/home/web/board/ read.do? menuId=10457\&boardMasterId=744\&boardCategoryId=\&boardId= 961610 (accessed on 20 June 2020).

2. Chin, T.A.; Tat, H.H.; Sulaiman, Z. Green supply chain management, environmental collaboration and sustainability performance. Procedia CIRP 2015, 26, 695-699. [CrossRef]

3. Yadav, R.; Pathak, G.S. Determinants of consumers' green purchase behavior in a developing nation: Applying and extending the theory of planned behavior. Ecol. Econ. 2017, 134, 114-122. [CrossRef]

4. Albayrak, T.; Aksoy, Ş.; Caber, M. The effect of environmental concern and scepticism on green purchase behaviour. Mark. Intell. Plan. 2013, 31, 27-39. [CrossRef]

5. Moser, A.K. Thinking green, buying green? Drivers of pro-environmental purchasing behavior. J. Con. Mark. 2015, 32, 167-175. [CrossRef]

6. Olson, E.L. It's not easy being green: The effects of attribute tradeoffs on green product preference and choice. J. Acad. Mark. Sci. 2013, 41, 171-184. [CrossRef]

7. Paul, J.; Modi, A.; Patel, J. Predicting green product consumption using theory of planned behavior and reasoned action. J. Retail. Con. Serv. 2016, 29, 123-134. [CrossRef]

8. Liobikienè, G.; Mandravickaitè, J.; Bernatonienè, J. Theory of planned behavior approach to understand the green purchasing behavior in the EU: A cross-cultural study. Ecol. Econ. 2016, 125, 38-46. [CrossRef]

9. D'Souza, C.; Taghian, M. Green advertising effects on attitude and choice of advertising themes. Asia Pac. J. Mark. Logist. 2005, 17, 51-66. [CrossRef]

10. Ta, H.; Esper, T.; Hofer, A.R. Business-to-consumer (B2C) collaboration: Rethinking the role of consumers in supply chain management. J. Bus. Logist. 2015, 36, 133-134. [CrossRef]

11. Boyce, W.S.; Mano, H. An inquiry into the supplier selection decision from the business-to-consumer (B2C) perspective. J. Bus. Ind. Mark. 2018, 33, 1221-1230. [CrossRef]

12. Green, K.W.; Zelbst, P.J.; Meacham, J.; Bhadauria, V.S. Green supply chain management practices: Impact on performance. Supp. Chain Manag. 2012, 17, 290-305. [CrossRef]

13. Sarkis, J.; Zhu, Q.; Lai, K.H. An organizational theoretic review of green supply chain management literature. Int. J. Prod. Econ. 2011, 130, 1-15. [CrossRef]

14. Zhu, Q.; Sarkis, J.; Lai, K.H. Institutional-based antecedents and performance outcomes of internal and external green supply chain management practices. J. Purch. Supply Manag. 2013, 19, 106-117. [CrossRef]

15. Han, H.; Kim, Y. An investigation of green hotel customers' decision formation: Developing an extended model of the theory of planned behavior. Int. J. Hosp. Manag. 2010, 29, 659-668. [CrossRef]

16. Yeon Kim, H.; Chung, J. Consumer purchase intention for organic personal care products. J. Con. Mark. 2011, 28, 40-47. [CrossRef]

17. Zhu, Q.; Sarkis, J. Relationships between operational practices and performance among early adopters of green supply chain management practices in Chinese manufacturing enterprises. J. Oper. Manag. 2004, 22, 265-289. [CrossRef]

18. Ajzen, I. The theory of planned behavior. Organ. Behav. Hum. Decis. Process. 1991, 50, 179-211. [CrossRef]

19. De Leeuw, A.; Valois, P.; Ajzen, I.; Schmidt, P. Using the theory of planned behavior to identify key beliefs underlying proenvironmental behavior in high-school students: Implications for educational interventions. J. Environ. Psychol. 2015, 42, 128-138. [CrossRef]

20. Ajzen, I. The theory of planned behaviour: Reactions and reflections. Psychol. Health 2011, 26, 1113-1127. [CrossRef] 
21. Hsu, C.L.; Chang, C.Y.; Yansritakul, C. Exploring purchase intention of green skincare products using the theory of planned behavior: Testing the moderating effects of country of origin and price sensitivity. J. Retail. Con. Serv. 2017, 34, 145-152. [CrossRef]

22. Joshi, Y.; Rahman, Z. Factors affecting green purchase behaviour and future research directions. Int. Strateg. Manag. Rev. 2015, 3, 128-143. [CrossRef]

23. Arvola, A.; Vassallo, M.; Dean, M.; Lampila, P.; Saba, A.; Lähteenmäki, L.; Shepherd, R. Predicting intentions to purchase organic food: The role of affective and moral attitudes in the theory of planned behaviour. Appetite 2008, 50, 443-454. [CrossRef] [PubMed]

24. Steg, L.; Vlek, C. Encouraging pro-environmental behaviour: An integrative review and research agenda. J. Environ. Psychol. 2009, 29, 309-317. [CrossRef]

25. Zhu, Q.; Sarkis, J.; Cordeiro, J.J.; Lai, K.H. Firm-level correlates of emergent green supply chain management practices in the Chinese context. Omega 2008, 36, 577-591. [CrossRef]

26. Seuring, S.; Müller, M. From a literature review to a conceptual framework for sustainable supply chain management. J. Clean.Prod. 2008, 16, 1699-1710. [CrossRef]

27. Zhu, Q.; Sarkis, J.; Lai, K.H. Choosing the right approach to green your supply chains. Mod. Supply Chain Res. Appl. 2019, 1, 54-67. [CrossRef]

28. Dou, Y.; Zhu, Q.; Sarkis, J. Green multi-tier supply chain management: An enabler investigation. J. Purch. Supply Manag. 2018, 24, 95-107. [CrossRef]

29. McDonald, S.; Oates, C.J. Sustainability: Consumer perceptions and marketing strategies. Bus. Strategy Environ. 2006, 15, 157-170. [CrossRef]

30. Stolze, H.J.; Mollenkopf, D.A.; Flint, D.J. What is the right supply chain for your shopper? Exploring the shopper service ecosystem. J. Bus. Logist. 2016, 37, 185-197. [CrossRef]

31. Wu, S.I.; Jang, J.Y. The impact of ISO certification on consumers' purchase intention. Total Qual. Manag. Bus. Excell. 2014, 25, 412-426. [CrossRef]

32. Rahbar, E.; Wahid, N.A. Investigation of green marketing tools' effect on consumers' purchase behavior. Bus. Strategy Ser. 2011, 12, 73-83. [CrossRef]

33. Hoejmose, S.; Brammer, S.; Millington, A. "Green" supply chain management: The role of trust and top management in B2B and B2C markets. Ind. Mark. Manag. 2012, 41, 609-620. [CrossRef]

34. Thøgersen, J.; Jørgensen, A.K.; Sandager, S. Consumer decision making regarding a 'green' everyday product. Psychol. Mark. 2012, 29, 187-197. [CrossRef]

35. Hair, J.F.; Black, W.C.; Babin, B.J.; Anderson, R.E. Multivariate Data Analysis, 8th ed.; Cengage: Andover, UK, 2019.

36. Nyilasy, G.; Gangadharbatla, H.; Paladino, A. Perceived greenwashing: The interactive effects of green advertising and corporate environmental performance on consumer reactions. J. Bus. Ethics 2014, 125, 693-707. [CrossRef] 